\title{
Space Weather: Historical and Contemporary Perspectives
}

\author{
Louis J. Lanzerotti ${ }^{1}$
}

Received: 3 June 2017 / Accepted: 4 August 2017 / Published online: 4 September 2017

(C) The Author(s) 2017. This article is published with open access at Springerlink.com

\begin{abstract}
A somewhat personalized overview is presented of the effects of solar-terrestrial processes on electrical technologies, beginning with the electrical telegraphs in the mideighteenth century to the current era of extensive ground- and space-based commercial and governmental technical systems (including national security) upon which modern society depends. As human technologies increased in diversity over the last century and a half, space weather effects have continued to be of significant importance in the successful design and operations of many of these technologies.
\end{abstract}

Keywords History $\cdot$ Space weather $\cdot$ Electrical technologies

\begin{abstract}
"...during the appearance of the aurora borealis of November 17, 1848, the soft iron armatures employed in the electric telegraph between Florence and Pisa remain attached to their electromagnetics, as if the latter were powerfully magnetized, without, however, the apparatus being in action, and without the currents in the battery being set in action." (Prescott 1875).
\end{abstract}

\section{Introduction}

Within a few decades in the early to mid 19th century, the electrical telegraph had revolutionized communications within countries, and across countries and oceans (Standage 1998). The telegraph had eliminated the line of sight semaphore signaling that had begun to be emplaced across Europe in the late 18th century (Napoleon had planned a line to Boulogne in preparation for his invasion of England), and in the eastern U.S. For optimum

The Scientific Foundation of Space Weather

Edited by Rudolf von Steiger, Daniel Baker, André Balogh, Tamás Gombosi, Hannu Koskinen and Astrid Veronig

\footnotetext{
$凶$ L.J. Lanzerotti

1j1@njit.edu

1 Center for Solar Terrestrial Research, New Jersey Institute of Technology, Newark, NJ 07102, USA
} 
signaling, semaphores were placed in so far as feasible on elevated locations ("telegraph hills"). Such signaling required significant manpower for relaying, and could often be obscured by weather. The electrical telegraph was a communications revolution, much faster than semaphores and not affected by visible weather. But the telegraph could be disturbed by electrical discharges from lightning.

The development of an electric telegraph of some type was of considerable importance to railway companies of the 19th century as railroads expanded across various nations. For example, as written in 1838 with respect to the development of telegraphs, "Probably no subject will contribute more to guard railway travellers [sic] against the accidents of collisions than the perfection of some rapid mode of communications from station to station, by giving timely notice of whatever may be on the road" (Electro-Magnetic Telegraphs 1838). That the electrical telegraph still required considerable development at that time were these hopeful words "And as it is thought that electro-galvanic telegraphs, if they can ever be perfected, bid fair to be among the most useful....". Thus the beginnings of the first technology-for communications - that would be subject to space weather.

Some sixty or more claimants to the concept of the telegraph existed up to about 1838 (Prescott 1875, page 425). But the February 1854 U.S. Supreme Court decision (Silverman 2003) settled the issue once and for all that the telegraph embodiment by Samuel F.B. Morse was the patent that counted: "Writing, printing or recording at a distance ... was never invented, perfected, or put into practical operation, till it was done by Morse." (Standage 1998, page 183).

The electrical telegraph operated under the simple principal that a long wire, with its attached telegraph key, was attached to a battery whose other pole was grounded by a conducting plate buried in the Earth. The wire at the other end was attached to a receiver that in turn was affixed to a wire connected to a conducting plate also buried in the ground. Thus, the Earth provided the return electrical path. However, Morse's original line in 1844 from Washington to Baltimore (along the Baltimore \& Ohio Railroad Company tracks), which carried the first words (in Morse code) "What hath God wrought", consisted of two wires, that is, an "entire metallic circuit" (Prescott 1875, page 54). This line therefore did not need the Earth for a return circuit. The biblical phrase that was transmitted was suggested by the mother of Annie Ellsworth, the daughter of Henry Ellsworth, the Commissioner of Patents and a Yale classmate of Morse (Silverman 2003).

Studies of the Earth as a conductor were carried out by a significant number of "philosophers" in the early 19th century, many in the context of studies of various types of electrical telegraphy. Such individuals included Gauss and Steinheil in Germany, Bain and Wheatstone in England, and Matteucci in Italy (Prescott 1875). The conclusion to use the Earth as a return conductor in this first electrical technology - a technology of long conductors - is the underlying reason why what is now called space weather became of significant importance to any technical system that needed long conductors for its implementation.

The following broad overview of space weather and aspects of its historical contexts are influenced by the author's personal experiences and research in the field, as well as by discussions and collaborations with national and international colleagues over many decades. This overview is not intended to be a comprehensive historical accounting, but rather the providing of a number of important, by the author's judgment, technical developments and occurrences as space weather became an ever-more prevalent element in the design and operations of many technologies. A Resource Letter on space weather by Baker and Lanzerotti (2016) contains some historical and more contemporary references.

The underlying theme of this overview is 
as human technologies increased in number, and especially in diversity, over the last 170 or so years, space weather effects have continued to be of significance in the successful design and operations of many of these technologies-particularly those used for communications and navigation, for both civilian and national security objectives.

\section{Technologies Based upon Long Conductors}

Long conductors with groundings at both ends are subject to what are now commonly called geomagnetically-induced currents (GICs) or telluric currents or earth currents. Space weather processes originating in the Sun produce these currents. From the earliest electrical technology employing long conductors until about 1940, GICs were the nemesis of, first, telegraph lines and then telephone circuits. Following the ever-more interconnectedness of power systems on all continents beginning in the mid-20th century, and especially the geomagnetic event of Easter Sunday in March 1940, the effects of GICs on power grids have become of very significant interest and concern. Knipp (2015) organized and moderated a collection of contemporary GIC-related publications, largely from American Geophysical Union journals, on GICs, and their especial present-day relevance to electrical power systems (Gaunt 2016).

Unknown currents were observed on the early electrical telegraphs, causing anomalous operations of the receivers. The first documentation of these spontaneous currents was in a publication by William Henry Barlow, an English civil engineer who at the time was the superintendent engineer of the Midland Counties Railway. Barlow (1849) reported that his "attention was strongly drawn to the subject" by his observation that during an aurora on the evening of May 19, 1847, "strong alternating deflections occurred on all the [telegraph] instruments". He further wrote that "... in every case which has come under my observation, the telegraph needles have been deflected whenever aurora has been visible".

Barlow determined to make "a systematic set of observations". He executed an experimental observation program employing spare, unused telegraph wires along the rail lines. First, he determined experimentally that only when both ends of a wire were connected to the ground were these spontaneous currents observed: not when only one end was grounded, or when the wire was floating. Then he took five-minute data on the position of the needle of a galvanometer over a two-week period. A plot of the tabular mean hourly data (from five minute observation points) in Barlow's publication from the Derby galvanometer for the Derby to Birmingham railway line $(\sim 70 \mathrm{~km})$ is shown in Fig. 1.

These data taken in May 1847 show large excursions in the galvanometer deflections during these two weeks (weekend days of data apparently not taken). Large daily excursions are seen during each week, and especially so during the first week. Barlow remarked about the occurrences of these diurnal variations. His measurements on these telegraph lines can be considered to represent the first observations of what is now well known as the ionosphere Sq current system (e.g., Matsushita 1969).

These diurnal variations remained puzzles to telegraph operators and engineers for years. For example, Richard Spelman Culley, an English engineer, listed the times of maximum excursion of diurnal galvanometer readings at stations located from Madras (now Chennai) to Munich to England to Ireland and to Toronto (Culley 1874). He stressed that the times of greatest and least diurnal excursion of the galvanometer needles "differ according to locality", but did not draw any conclusions as to the possible origin of the excursions.

Barlow includes in his paper as a Postscript a communication from Culley dated May 8, 1848. Culley writes that he has "twice this winter foretold an aurora: the connection between 


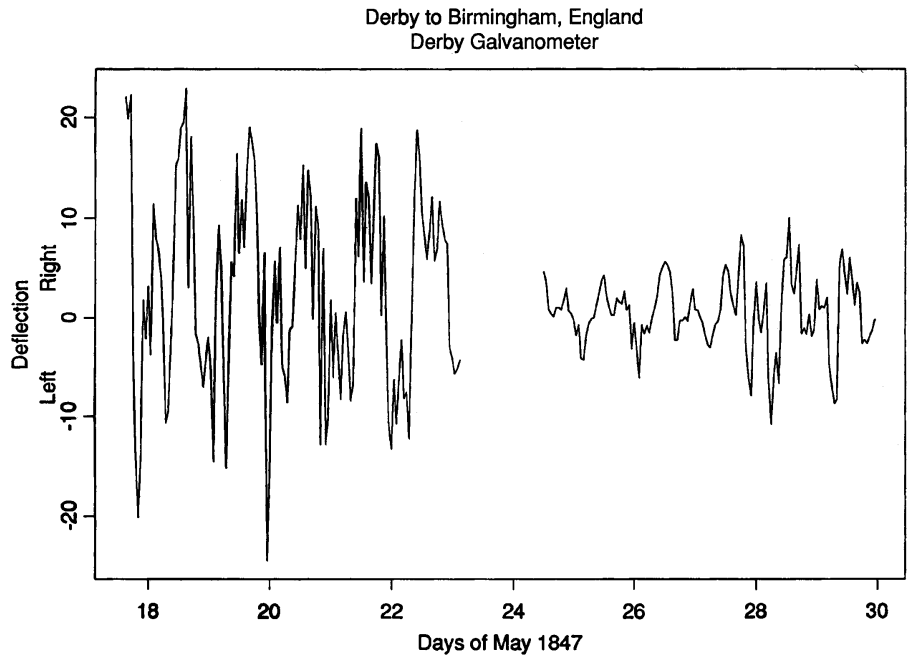

Fig. 1 Hourly mean declination readings of the Derby galvanometer on a telegraph line from Derby to Birmingham of the Midland Counties Railway Company. Adopted from tabular data in Barlow (1849)

this phenomenon and the deflections [of a galvanometer needle] is indisputable." In the section devoted to Earth Currents in his Handbook, Culley (1874) writes "The telegraph always foretells an aurora". These remarks by Culley could be considered the initial steps in the "forecasting" of solar-terrestrial processes and of space weather effects on technical systems. Prior to Culley's proposal of a technology (the telegraph) foretelling an aurora, a correlation of auroral sightings and deflections of a compass needle showing magnetic activity was studied in the early 18th century by the Swedish scientists Anders Celcius and his student Olof Hiorter (e.g., Odenwlad 2007).

Much has been written and compiled about the exceptionally large geomagnetic storm interval that followed the observation of the first white light solar flare by Richard Christopher Carrington in 1859 (Carrington 1863), more than a decade after the work of Barlow. Prescott (1875), Superintendent of Electric Telegraph Lines in Boston, reports extensively on the telegraph impacts of the geomagnetic activity during the interval from August 28th through about September 2nd, 1859. A 120 page volume on the event as it affected telegraph systems was written soon afterwards by Clement (1860). Shea and Smart (2006) compiled a set of eight articles on the Carrington event that were published in the American Journal of Science in the two-year period following the event.

In more recent times, space weather has become of considerably more interest and importance in the context of solar-terrestrial effects on technological systems. This 1859 geomagnetic storm ("the Carrington event") has served as the reference point for defining great storms, and for identifying impacts from such a great storm on contemporary technologies, including long conductors (e.g., Cliver 2006; National Academies 2008; Tsurutani et al. 2003; Siscoe et al. 2006; Clauer and Siscoe 2006; Baker et al. 2013; Chigomezyo et al. 2013).

Prescott $(1860,1875)$ records a number of first hand experiences of the telegraph operators during the Carrington event. Other of his observations, and of a number of other operators in the U.S. and Europe, are contained in the eight articles compiled by Shea and Smart (2006). They all make for interesting reading. A flavor of the experiences of operators can be obtained from an exchange that Prescott $(1860,1875)$ records between operators in 
Fig. 2 Old trans-Atlantic telegraph cables entering from Trinity Bay into the historic Heart's Content, Newfoundland, cable station (red building in background)

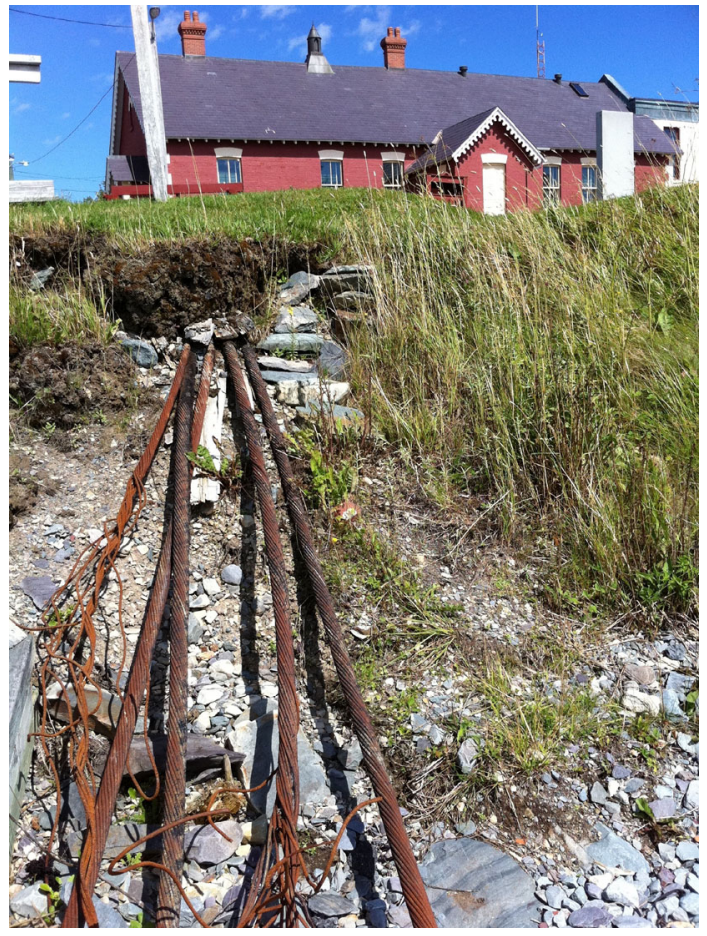

Boston and Portland, Maine. The two operators discuss the huge anomalous current situation they are experiencing. They decide to try to operate without their batteries. The Boston operator is quoted as writing to the Portland operator "We are working with the aid of the aurora alone. How do you receive my writing?" The Boston operator responds "Very well indeed, much better than when the batteries were on; the current is steadier and more reliable." Prescott (1875) concludes by noting that the Boston-Portland line "was worked in this manner more than two hours, when, the aurora having subsided, the batteries were resumed."

The successes of telegraph on land led quickly to extend communications across bodies of water (e.g., Newfoundland to New York), and the Atlantic Ocean. The saga of the American Atlantic cable entrepreneur Cyrus Field, who made his fortune in the paper industry, has been recorded in many volumes (e.g., Standage 1998; Gordon 2003; Rowe 2009). The initial cable laid in 1858, from Valentia, Ireland, to Bull Arm (Trinity Bay), Newfoundland, failed after about one month. Finally, success was achieved in 1866 with the connection from Valentia to Heart's Content (Trinity Bay), Newfoundland (Fig. 2). So successful was it, the Heart's Content cable station was in operation for telegraphy for essentially a century, until 1965.

Thus, the first Atlantic cable missed recording the 1859 Carrington event. Nevertheless, as Rowe (2009) relates for the transatlantic connection, "the beginning of cable service was far from reliable [...] earth's magnetic currents, the aurora borealis [...] sent the [galvanometer] into wild and rapid gyrations." Gordon (2003) relates that as the cable was being laid there was a "tiny whispering effect [of] the earth's magnetic field [...] on the current in the cable."

It is of interest in the context of the history of space weather that the individual who was centrally involved in engineering the solution to the transmission of signals in undersea 
Fig. 3 Voltage at the AT\&T Oban, Scotland, telecommunications station on one of the two Oban to Clarenville, Newfoundland, TAT-1 cables during the February 11, 1958, geomagnetic storm. Adapted from Axe (1968)

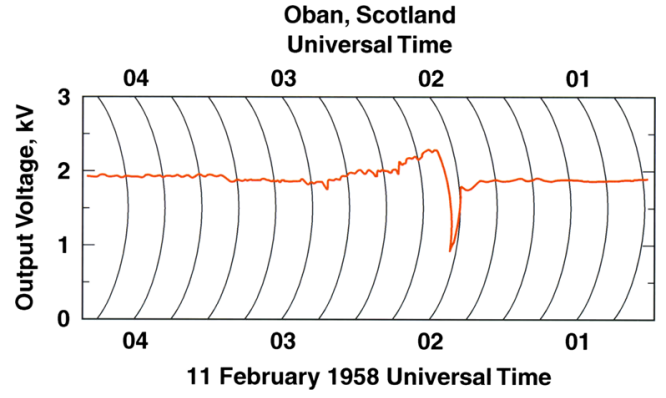

cables was also the individual who was most influential in arguing against the effect of the sun on geomagnetism and the aurora, and thus on the production of large earth currents that disturbed telegraph systems. Sir William Thomson (Lord Kelvin, Kelvin being the name of the small river near the campus of the University of Glasgow where Thomson spent his career) addressed and provided solutions for the data rate problem for a cable that is laid in the conducting medium of seawater (Lindley 2004). Lord Kelvin's 1892 address to the Royal Society is often cited as the summary basis for his influence in shaping the intellectual opposition to solar influences on the aurora, and thus earth currents (Kelvin 1892).

The huge geomagnetic storm event of May 14-15, 1921, was of particular interest in that Washington, DC, "was cut off telegraphically from the rest of the United States" (Odenwald 2015). The New York Times (May 15, 1921) carried a front page story where "The American Telegraph and Telephone Company ... reported that the disturbance [on its lines] was unprecedented in the memory of the men thirty years in the service. At times, every wire was 'down' and operators could not get them back into service although they kept trying to communicate with city after city." Anderson (1928) wrote that during the geomagnetic storm "... grounded telegraph circuits were rendered inoperative due to excessive earth potentials which burned out line protectors, broke down condensers and insulation, and even started fires in terminal offices."

As the complexities of technical systems increase, as new technologies are invented and employed, human-built systems can be susceptible to the effects of earth's space environment. This is exemplified by the advance made in communications when cables (long conductors) were laid under the Atlantic to carry not telegraph, but telephone, traffic. The first transatlantic telephone circuits were established in September 1956, nearly a century after the first telegraph cable. This telephone cable from Oban, Scotland, to Clarenville, Newfoundland, consisted of two cables, one carrying voice from Oban to Clarenville and the other carrying voice in the reverse direction. The cable was retired after two decades, in 1978. A year and a half after the start of telephone transmissions, the magnetic storm of 10 February 1958 produced about an hour disruption of telephone traffic on the cable (Axe 1968; Meloni et al. 1983).

Because of the widespread disturbances, including on power lines, that the 1958 magnetic storm event caused, an article in the New Yorker magazine was devoted to it (Brooks 1959). Brooks wrote that "At almost the exact moment when the magnetograph traces leaped and the aurora flared up, huge currents in the earth, induced by the heavenly turbulence, manifested themselves not only in power lines in Canada but in cables under the north Atlantic". Voltage excursions on the telephone power supply at Oban exceeded $1 \mathrm{kV}$ to produce the communications disruption (Fig. 3; Axe 1968).

Swedenborg and Wyke (1959) documented effects in the communications systems in Sweden during the February 1958 storm. Effects included voltage swings, spurious alarms, 
Fig. 4 Areas of high Earth resistivity (black shaded areas) with locations shown (open circles) of AT\&T Long Lines system telecommunications problems during the Easter Sunday, March 24, 1940, geomagnetic storm. Adapted from Germaine (1940)

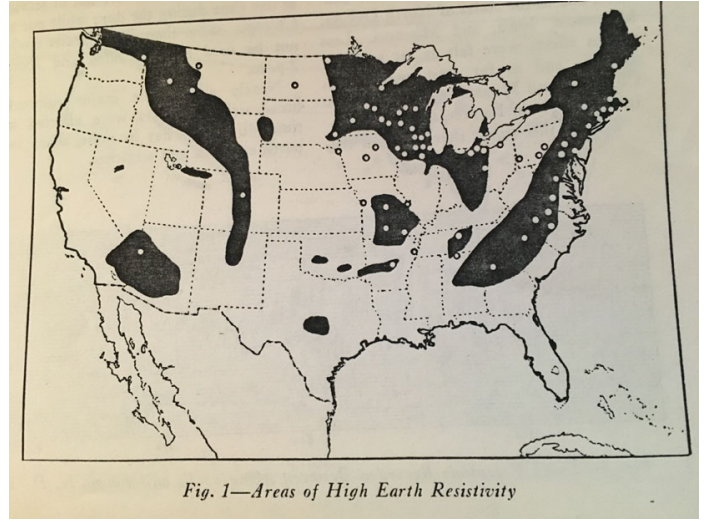

and even fire in some cables. They wrote "The effects of the magnetic storm of 11th February 1958 stressed the need of an immediate inquiry into the possibilities of organizing an efficient warning service and the means of providing for preventive measures." They also wrote that the "proposed warning service should be organized so as to avoid as far as possible the emission of unnecessary warnings." These features remain today pillars for space weather forecast and modeling services.

Brooks further noted with respect to the February 1958 event "circuit breakers began tripping out in Ontario transformer stations, plunging the Toronto area into a temporary darkness broken only by the strange light of the aurora overhead." This 1958 storm was not the first large and widespread disturbance of long conductor electric power systems. That can be attributed, in so far as I have determined, to the very large Easter Sunday 24 March 1940 geomagnetic storm (e.g., Nicholson 1940; McNish 1940; Davidson 1940) that disrupted telegraph, telephone, and electrical power across a considerable portion of the U.S. The Edison Electric Institute convened a meeting in Chicago in May 1940, just after the March event at which representatives of telephone and power companies made presentations on the event.

Davidson (1940) provided a lengthy list and discussion of impacts on power companies in the U.S. and Canada from the March 1940 storm. Disturbances were recorded by 10 companies in New England, New York, eastern Pennsylvania, and southern and eastern parts of Minnesota, and in Ontario and Quebec. There were 7 cases of voltage dips, 5 cases of tripping transformer banks, and 4 cases of large surges or swings in reactive power.

Germaine (1940), in his discussion of the effects of the March 1940 storm, notes that the highest voltages across telephone cables "as a rule will be experienced in those territories where the earth resistivity is highest...." He presented a map of the continental U.S. showing high resistivity areas (shaded black in Fig. 4) and locations where anomalies were seen in the AT\&T Long Lines system (open dots in Fig. 4). A sample of large voltage swings (as much as $500 \mathrm{~V}$ overall) for several hours on the line from Minneapolis to Fargo is shown in Fig. 5 (Germaine 1940). The communications impacts of the 1940 event were sufficient to warrant a one-page article in Life Magazine (1940). The article reproduced Germaine's resistivity map as well as contained three pictures of the originating sunspot region moving across the solar disk.

Beginning in the decade preceding the March 1940 event, a cooperative project of the United States Coast and Geodetic Survey, the Carnegie Institution of Washington, and the AT\&T Company carried out studies of earth currents at the Tucson magnetic observatory in Arizona (Rooney 1949). This program, lasting from 1931 until 1943, resulted in nearly 
Fig. 5 Minneapolis, Minnesota, to Fargo, North Dakota, Earth potential recorded on AT\&T telecommunications line during the March 24, 1940, geomagnetic storm. Adapted from Germaine (1940)

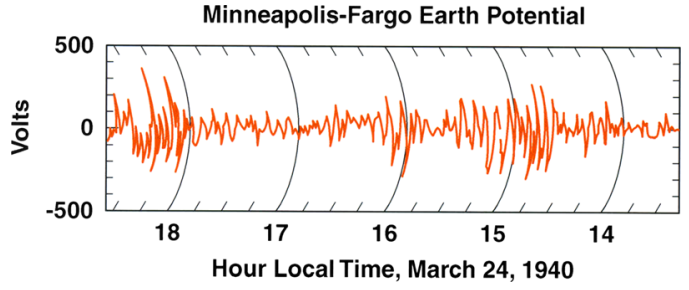

12 years (approximately a solar cycle) of coincident magnetic and telluric current studies. As stated by Rooney, such earth current data were rare in the literature. He further stated that the only exception that he knew were from 1910-1938 at the Ebro, Spain, observatory, which published hourly values in its Monthly Bulletins. The interests of Bell Laboratories, and thus AT\&T, in this project undoubtedly were as a result of the GIC problems that continued to occur in long telephone lines. Employed in the Tucson-based study were unused, approximately orthogonal, lines of the Mountain States Telephone and Telegraph Company. One line ran $90 \mathrm{~km}$ due east of Tucson and one ran about $60 \mathrm{~km}$ a little east of north. It is not clear how the results of these studies may have influenced the operations of long conductor AT\&T telephone lines.

Following the 1958 event, at the beginning of the space age, concern for long conductors began to become more centered on electric power grids. For example, the very large solar event of August 1972 (occurring between the last two Apollo flights to the moon) caused power disruptions in regions as widespread as Newfoundland, Wisconsin, South Dakota, and Manitoba, and destroyed a transformer in British Columbia (Odenwald 2015). An AT\&T long lines telephone cable from Plano, IL, to Cascade, IA, was rendered out of service (Anderson et al. 1974). Geomagnetic depth sounding studies of the Plano-Cascade region were carried out (Meloni et al. 1985). Design changes were made in telephone cable power systems following this 1972 event. The changes in the powering system would appear to have prevented the outage of the first transatlantic fiber cable (Medford et al. 1989) in the March 1989 geomagnetic storm that caused the electrical power blackout of the province of Quebec (Czech et al. 1989).

A considerable amount of research was conducted in the high resistivity area of northern Minnesota (Fig. 4), stimulated by space weather effects on power systems (e.g., Albertson et al. 1970, 1974; Kappenman 1996). The large geomagnetic storm of March 1989 which blacked out Quebec, and the "Halloween storm" of 2003 produced a large increase in research and development related to geomagnetic storm effects on long conductors, both in the U.S. and in Europe (e.g., Czech et al. 1989; Bolduc 2002; Kappenman 2005; National Academies 2008; Wik et al. 2009; Royal Academy of Engineering 2013).

Pipelines are another class of long conductor that can be affected by anomalous space weather-induced telluric currents. These earth currents can produce enhanced erosion of pipelines if there are breaks in insulation, and can cause disturbances and outage of corrosion-protection electronics (e.g., Campbell 1978, 1980; Viljanen et al. 2006).

While there has been considerable research on individual events, and modeling to address such events, statistics on the occurrence and occurrence frequency of GICs in specific locations are few. Such statistics would be useful in achieving deeper understanding of local ground conductivities in specific areas, and the overhead ionosphere current systems that can develop in geomagnetic disturbances. Studies of this nature include Lanzerotti et al. (1993) and Pulkkinen et al. (2012). The lengthy data set of Rooney (1949) has never been analyzed in a statistical manner. 


\section{Wireless Technologies}

The first wireless telegraph signals using electromagnetic waves were sent by Guglielmo Marconi in 1895. He carried out many experiments from his parent's home in Villa Griffone outside Bologna (Weightman 2003). Marconi was one of many in Europe, the UK, and the U.S. who were intrigued by the possibility to send Morse Code signals by the electromagnetic waves that had been discovered by Heinrich Hertz based upon the theoretical work of electromagnetic forces proposed by James Clerk Maxwell.

Marconi was an astute businessperson as well as talented in exploiting technology. He recognized that his ship-to-shore wireless businesses in England could, and should, be extended to intercontinental distances. He achieved a demonstration of this with the reception of the Morse code letter "S" (dot dot dot) in blizzard conditions on Telegraph Hill, St. John's, Newfoundland, on the 12th and 13th of December 1901 (Weightman 2003). There had been considerable skepticism surrounding Marconi's belief that the wireless signals transmitted from Poldhu on Cornwall would be received across the curvature of Earth. Of course, the reason why this achievement was possible (and that the Poldhu signals did not just propagate off into space) was the existence of the as-yet-to-be discovered ionosphere. And the ionosphere would be the geophysical entity that would be influenced by space weather phenomena. Breit and Tuve (1925) and Appleton and Barnett (1925) physically identified the reflecting layer more than two decades later. Marconi (1909) and Appleton (1947) were awarded Nobel prizes for their work. It is relevant to note that in the final paragraph of his Nobel Prize Lecture, Sir Edward Appleton addressed the "practical side of applications". He discussed the "forecast of what I may call the 'ionosphere weather' some time ahead" for the "most suitable wavelengths at any time of the day, over any distance of transmission, at any part of the world." His phrase "ionosphere weather" is a forerunner to today's "space weather".

Wireless telegraphy was the second human-built system that was, unbeknownst to Marconi and subsequent developers, susceptible to space weather effects in Earth's space environment. The same electrical currents in Earth's ionosphere that produced the "spontaneous" telluric currents that disrupted cable telegraph could also disrupt the propagation and reception of long-distance wireless signals. Wireless engineers noted this at the time, and Marconi wrote (1928) “... times of bad fading [of radio signals] practically always coincide with the appearance of large sun-spots and intense aurora-borealis usually accompanied by magnetic storms...." He importantly noted that these are "... the same periods when cables and land lines experience difficulties or are thrown out of action."

The telephone communications industry early saw the importance of wireless for voice transmission. And also experienced the effects of space weather on transmissions, as illustrated in Fig. 6 (reproduced from Fagen 1975, which contains information on early wireless research in the former Bell Telephone System). The intensities in the signal strength (upper curve) were obtained by averaging the signal strength values from about ten European stations that were broadcasting in the $\sim 15-23 \mathrm{kHz}$ band (very long wavelengths), after reducing them to the signal from Nauen, Germany, as the common base. The relationship of the signal strength to the monthly-averaged sunspot numbers per year for two solar cycles in the early 20th century is clear. The physical reason(s) for such an association was obscure at this time, of course, but such a relationship could provide communications engineers some gross expectations as to signal quality and strength on a year-to-year basis. Such an example of industrial interest in solar effects on wireless telephony can be associated with very early "forecasting" of space weather phenomena affecting technologies.

As described above, Marconi noted that disturbances on wireless transmissions occurred at the same time that wired communications were affected. The New York Times (May 15, 
Fig. 6 Upper trace: yearly transatlantic wireless signal strength ( $\sim 15-23 \mathrm{kHz}$ band) for approximately two solar cycles in the very early days of wireless telegraphy. Lower trace: yearly sunspot numbers. Adopted from Fagen (1975)

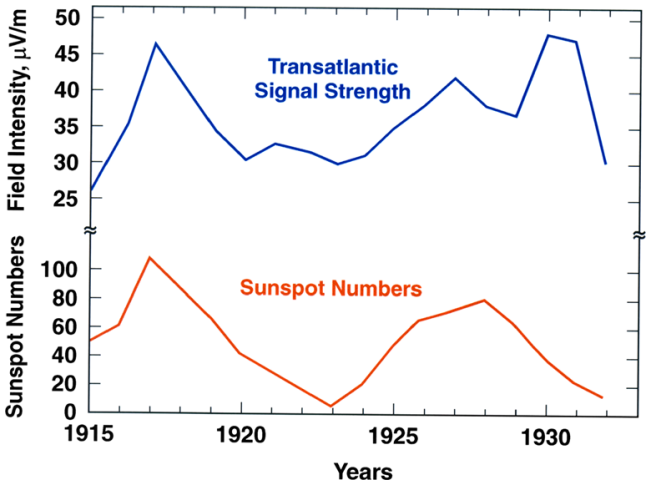

Fig. 7 Transatlantic wireless transmissions on two different frequencies (blue and red) during a geomagnetic storm in July 1928. Shown in green is the horizontal component of Earth's geomagnetic field (location unspecified). Adapted from Bowen (1930)

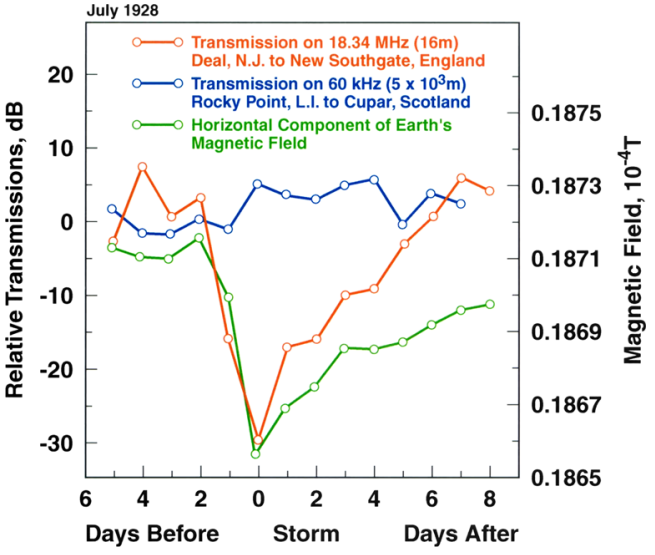

1921) reported, "Curiously, the disturbance [of May 15, 1921] that tied up the land wires seemed to strengthen the signals of the wireless apparatus. Operators in the special wireless station of The New York Times reported that their signals from Berlin and the Lafayette station at Bordeaux were much stronger [during] the period of the greatest disturbance on the land wires." Anderson (1928) provides transmission data from three locations in the eastern United States to Chelmsford, England, during this large event when both wireless and wired communication services were affected.

In fact, in those early days where the ionosphere was so important in facilitating transmissions (even though the ionosphere was not "discovered" or understood), geomagnetic storms would affect different frequencies in quite different ways. As The New York Times (January 23, 1938) subhead on a front-page article about the solar event of January 22, 1938 reported "Transoceanic Services Transfer Phone and Other Traffic to Long Wave Lengths as Sun Spot Disturbance Strikes". This is illustrated in Fig. 7 for a geomagnetic storm event in July 1928 (Bowen 1930). Here the transmissions at long wavelengths across the Atlantic were relatively undisturbed while those at the shorter wavelength were basically inoperable.

It is important to recognize that space weather effects did not abate and also did not hinder the commercialization of wired and wireless communications technologies. This is the general trend one finds in technology advances that can be affected by solar-induced processes. Bowen (1937) reviews the developments in transoceanic radiotelephone in the decade since the beginning of commercial service in January 1927. The technological ad- 
vances were huge. At the time (1937) that he writes, United States subscribers could reach 68 other countries, and the radiotelephone circuits that he illustrated in his Fig. 1 permitted the interconnection of "about ninety-three percent of the world's telephones". He does not once address solar effects in his review, even though he was an early engineer addressing the topic (Bowen 1930). As a side note, Ralph Bowen became research director at Bell Telephone Laboratories, and led the 1948 press conference that announced the invention of the transistor by John Bardeen, Walter Brattain, and William Shockley (the solid state device that revolutionized communications technologies, as well as spawned countless inventions and industries in many fields).

The use of electromagnetic waves in new technologies has exploded since the 1930s. Radar was first employed for offense and defense in WWII. British radars were temporarily blinded (with the blinding initially attributed to enemy jamming) by the large solar radio burst in February 1942 (Hewish 2002). The large solar event of May 1967, including the radio burst content (Castelli et al. 1968) that interfered with radar was recently re-visited by Knipp et al. (2016), who discussed the cold war implications. Solar radio noise and bursts continues to be of design and operational concern for the potential of interference with radar and navigation (GPS) technologies (e.g., Cerruti et al. 2006, 2008).

The ionosphere was found by the COMSAT engineer Taur $(1973,1976)$ to disturb even the $\mathrm{GHz}$ frequencies used for satellite-to-ground signals. The scintillation of these signals has proven to be a significant impediment to communications and navigation, especially in the equatorial and auroral regions (e.g., Basu and Basu 1981). The scintillations and disturbances of the signals by the ionosphere have critical implications for national security interests (e.g., Kelly et al. 2014).

Temporal changes in Earth's natural magnetic field due to geomagnetic disturbances and storms are used for geomagnetic depth sounding of Earth's crust and upper mantle (magnetotelluric technique). Geomagnetic field variations from minutes to many hours are measured and analyzed to investigate a large range of depths into the Earth (Chave and Jones 2012). Exploration for minerals, other resources of economic interest, and even archeological artifacts are often conducted by surveys using magnetic sensing instruments on land and from aircraft. Such surveys can be severely compromised if the geomagnetic conditions are disturbed (e.g., Reeves 1993). Thus, depending upon the objective, natural geomagnetic field variations can be either a source or a disturbance for exploration.

\section{Air and Space Technologies}

\subsection{Spacecraft Radiation Effects}

When shortly after WWII Sir Arthur Clarke proposed his crewed geosynchronous communications satellite, he did not envision that Earth's space environment would be anything but benign. Neither did John Pierce at AT\&T Bell Laboratories when he proposed the low altitude active communications satellite Telstar-1 (launched in July 1962). The surprising discovery by Van Allen (1959) with an instrument on the Explorer 1 satellite of the intense fluxes of radiation trapped in Earth's magnetic field meant that any technologies that humans placed into space would have to contend with this radiation. Research on Earth's (and the interplanetary medium) radiation environment continues at a high and sophisticated level to this day.

Extensive references are provided in Hastings and Garrett (2004), Baker and Lanzerotti (2016), and Pisacane (2016) on the effects of the space environment on space systems. The 


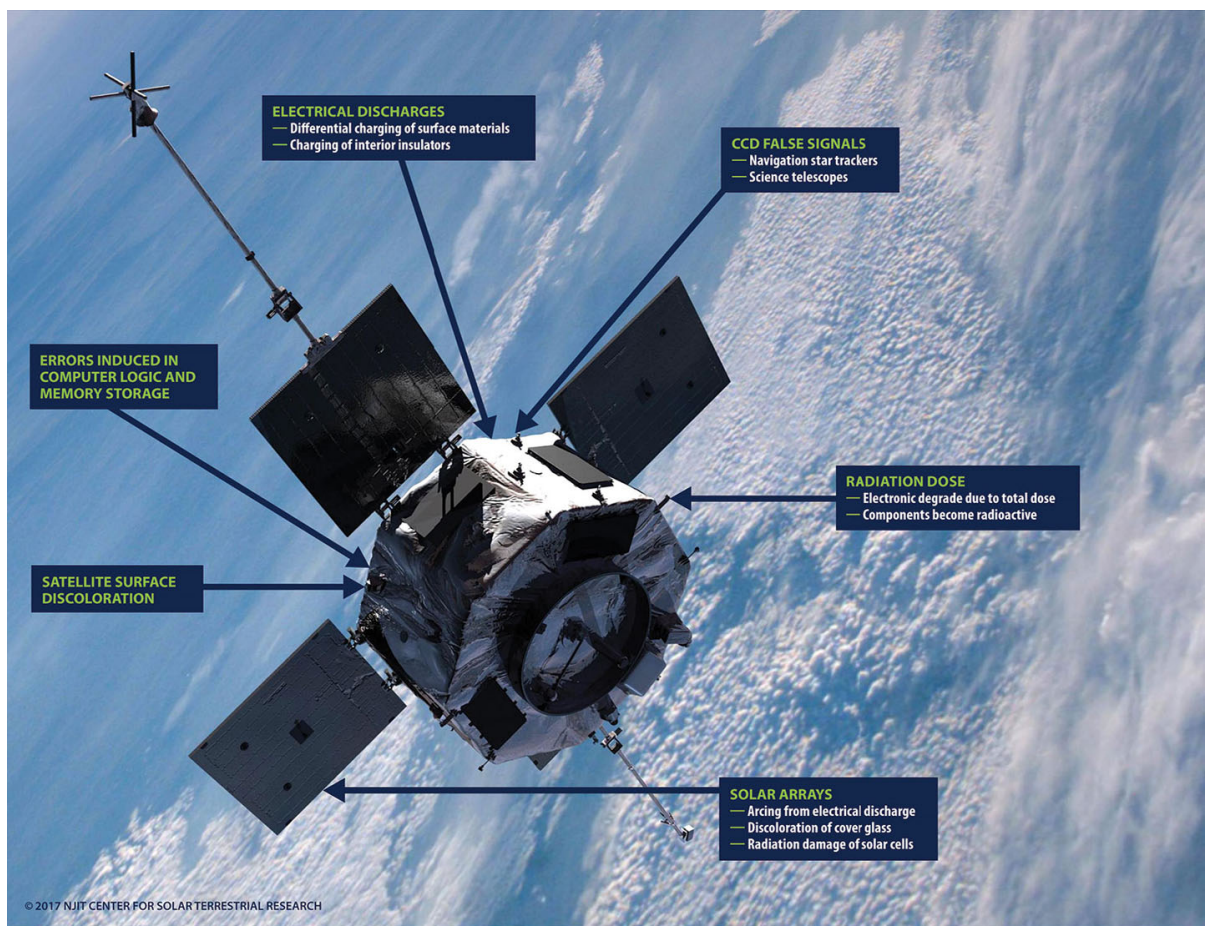

Fig. 8 Space radiation effects on space systems

major dominant radiation effects are illustrated in Fig. 8. Radiation impinging on solar arrays, on spacecraft surface materials, and on insulating materials deep within a spacecraft can produce high levels of charge buildup on the arrays and in the insulators (e.g., Vampola 1987; Lanzerotti et al. 1998; Garrett and Whittlesey 2012). When the charges become too large they will break down and will produce electromagnetic signals that can interfere with the satellite electronics (as an atmospheric lightning discharge produces interference in radio receivers).

Radiation will also discolor spacecraft surface materials (such as thermal insulations) and the cover glasses that are over the solar arrays (e.g., Bouquet and Phillips 1983). Radiation can also cause components on satellites to become radioactive. Errors will be induced in computer logic systems and solid-state memories (e.g., Lohmeyer et al. 2015; Clements et al. 2016). Radiation will induce false signals in scientific optical instruments and in sun and star trackers that are used for spacecraft attitude control (Birnbaum 1996).

As a space vehicle continues to reside within the radiation environment, the impinging radiation will slowly degrade the solar arrays, decreasing the power available to operations of the payload. Solar array degradation as measured on the Van Allen Probes B spacecraft for 1152 mission days post launch (August 30, 2012) is shown in Fig. 9. The degradation of two separate solar array patches on spacecraft B is illustrated. These data and the design of the solar arrays are presented in detail in Butler (2016). The sizes of satellite solar arrays are designed to take into account in so far as feasible such degradation over the time of the designed mission. 


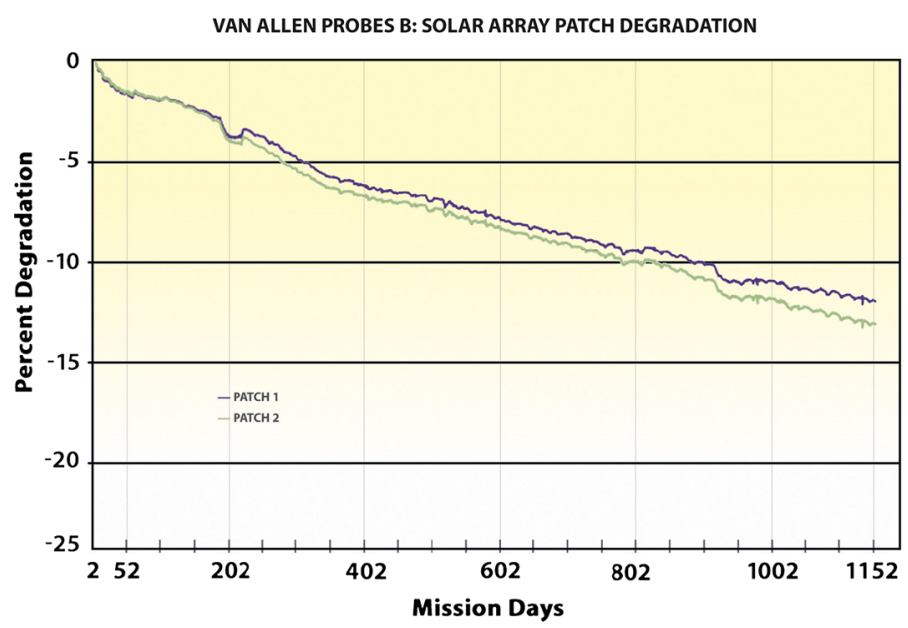

Fig. 9 Solar array patch degradation for two array patches on Van Allen Probes B normalized to Day 2 (August 31, 2012) of the mission. The data plotted are the short circuit current of each solar patch showing the decrease over the first 1100 days of the mission

\subsection{Satellite Drag}

Variations in the properties (density, composition, temperature, winds) of Earth's atmosphere above a few hundred $\mathrm{km}$ under differing solar and geomagnetic conditions are often referred to as the second major understanding of the space age, after the discovery of the radiation belts (Jacchia 1963). Studies of orbits of satellites at low Earth altitudes, and of satellites that have low altitude perigees, yield data that provide some of this atmospheric information (e.g., King-Hele 1992; Knipp et al. 2004; Moe and Moe 2011).

These data are also needed, and are used, in atmospheric models for the prediction of the orbits of satellites (and space debris) around Earth. Predictive orbital knowledge is essential for monitoring space assets of potentially hostile entities. Predictive knowledge of satellite orbits also is essential for spacecraft operators to adjust orbital conditions using on-board fuel. Adjusting satellite orbits can prolong lifetimes, and contribute to de-orbiting at the end of useful life. Predictions of the locations of space debris enable satellite operators (including those operating the International Space Station) to maneuver their satellites to avoid mission-ending collisions.

\subsection{Space Radiation at Aircraft Altitudes}

Aircraft flying at altitudes typical of jet airplane travel encounter galactic cosmic ray radiation because of reduced magnetic field and atmospheric shielding at flight altitudes (Knipp 2017). The amount of enhanced radiation depends upon the latitude of the flight paths; those at lower latitudes encounter less cosmic ray intensity due to the larger screening of Earth's magnetic field. Following the end of the cold war, aircraft from North America could fly the shorter, great circle, routes over the North Polar Region to reach Asian destinations, and vice versa. Such flight paths encounter more galactic cosmic rays. Further, and importantly, energetic solar particles from solar events can penetrate down polar magnetic field lines to jet flight altitudes. These solar particles can present substantially enhanced radiation conditions for such flights (e.g., Kataoka et al. 2015). 
Therefore, at typical airline altitudes space-originating radiation is a concern for its effects on aircraft avionics, for RF communications links, and for human exposure (e.g., Jones et al. 2005; Bennett et al. 2013; Tobiska et al. 2016). Airline companies and national security entities have incorporated aircraft radiation forecasts and warnings in their control centers. A great circle route can be altered if a solar particle event is expected over the polar region. The altered, lower latitude, longer duration route, which can often involve a re-fueling, adds considerably to the operational cost of a flight.

\section{Summary}

As Fig. 10 illustrates, enormous advances in technologies and technological systems have occurred since the development of the telegraph in the middle of the 19th century. Solarterrestrial occurrences can affect the design and operations of many of these systems as is illustrated schematically. Ground- and space-based systems are now ubiquitous not only for communications, but for navigation, weather, and critical national security purposes. Contemporary understanding of Earth's space weather environment, from the sun to the top of the atmosphere, has little comparison to Carrington's solar research.

Research on Earth's space environment has of necessity become more sophisticated in order to provide the "space weather" data required to design and operate the ground-based and satellite systems that use contemporary cutting edge technologies (Baker and Lanzerotti 2016). Because of its critical importance, frontier space environment research continues to be of high relevance and importance, and is supported by national governments and industry.

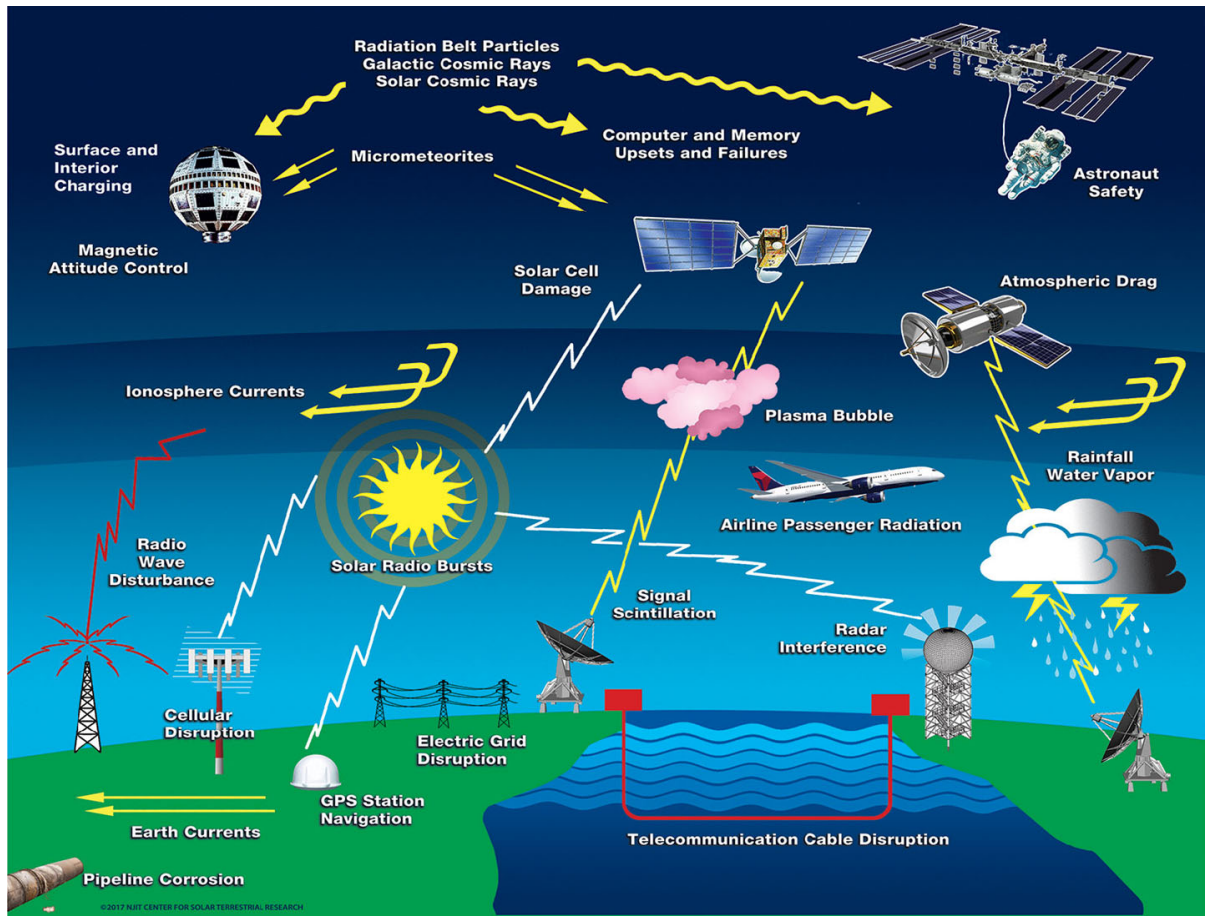

Fig. 10 Solar-terrestrial effects on contemporary technologies 
As technologies - whether on the ground or in space - that can be impacted by space processes continue to advance in sophistication, the understanding (and even predictability) of Earth's dynamic space weather environment will need to similarly advance in sophistication by forefront research in order to ensure operational success and mission survival.

Open Access This article is distributed under the terms of the Creative Commons Attribution 4.0 International License (http://creativecommons.org/licenses/by/4.0/), which permits unrestricted use, distribution, and reproduction in any medium, provided you give appropriate credit to the original author(s) and the source, provide a link to the Creative Commons license, and indicate if changes were made.

\section{References}

V.D. Albertson, S.C. Tripathy, R.E. Clayton, Electric power systems and geomagnetic disturbances, in Proc. Midwest Power Symposium (1970)

V.D. Albertson, J.M. Thorson Jr., S.A. Miske Jr., The effects of geomagnetic storms on electrical power systems. IEEE Trans. Power Appar. Syst. PAS-93, 1031 (1974)

C.W. Anderson III., L.J. Lanzerotti, C.G. Maclennan, Outage of the L4 system and the geomagnetic disturbances of 4 August 1972. Bell Syst. Tech. J. 53, 1817-1837 (1974). doi:10.1002/j.1538-7305.1974. tb02817.x

C.N. Anderson, Correlation of long wave transatlantic radio transmission with other factors affected by solar activity. Proc. IRE 16, 267 (1928)

E.V. Appleton, M.A.F. Barnett, Local reflection of wireless waves from the upper atmosphere. Nature 115, 333 (1925)

G.A. Axe, The effects of the Earth's magnetism on submarine cables. Post Off. Electr. Eng. J. 61, 37 (1968)

D.N. Baker, L.J. Lanzerotti, Resource letter SW1: Space weather. Am. J. Phys. 84, 166-180 (2016). doi:10. $1119 / 1.4938403$

D.N. Baker, X. Li, A. Pulkkinen, C.M. Ngwira, M.L. Mays, A.B. Galvin, K.D.C. Simunac, A major solar eruptive event in July 2012: Defining extreme space weather scenarios. Space Weather 11, 1 (2013). doi:10.1002/swe.20097

W.H. Barlow, On spontaneous electrical currents observed in the wires of the electric telegraph. Philos. Trans. R. Soc. Lond. 139, 61-72 (1849)

S. Basu, S. Basu, Equatorial scintillations: a review. J. Atmos. Terr. Phys. 43, 473-489 (1981)

L.G.I. Bennett, B.J. Lewis, B.H. Bennett, M.J. McCall, M. Bean, L. Doré, L. Getley, A survey of the cosmic radiation exposure of Air Canada pilots during maximum galactic radiation conditions in 2009. Radiat. Meas. 49, 103-108 (2013). doi:10.1016/j.radmeas.2012.12.004

M.M. Birnbaum, Spacecraft attitude control using star field trackers. Acta Astronaut. 39, 763 (1996)

L. Bolduc, GIC observations and studies in the hydro-Quebec power system. J. Atmos. Sol.-Terr. Phys. 64, 1793 (2002)

F.L. Bouquet, A. Phillips, Simulated space radiation effects on dielectrics and coatings. IEEE Trans. Nucl. Sci. 30, 4090 (1983)

R. Bowen, Transoceanic telephone service-Short-wave transmission. Bell Syst. Tech. J. 9, 258 (1930)

R. Bowen, Transoceanic radio telephone development. Bell Syst. Tech. J. 16, 560-567 (1937)

M.A. Breit, M.A. Tuve, A radio method of estimating the height of the conducting layer. Nature 116, 357 (1925)

J. Brooks, A reporter at large; The subtle storm, New Yorker (February 19, 1959)

M. Butler, The Van Allen Probes Power System Mission Performance, in AIAA Propulsion and Energy Forum, 14th International Energy Conversion Engineering Conference, Salt Lake City, UT (2016)

W.H. Campbell, Induction of auroral zone electric currents within the Alaska pipeline. Pure Appl. Geophys. 16, 1143 (1978)

W.H. Campbell, Observation of electrical currents in the Alaska oil pipeline resulting from auroral electrojet current sources. Geophys. J. R. Astron. Soc. 61, 437 (1980)

R.C. Carrington, Observations of the Spots on the Sun from November 9, 1853, to March 24, 1861, Made at Redhill (Williams and Norgate, London, 1863)

J.P. Castelli, J. Aarons, G.A. Michael, The great solar radio burst of May 23, 1967. Astrophys. J. 153, 267-273 (1968)

A.P. Cerruti, P.M. Kintner, D.E. Gary, L.J. Lanzerotti, E.R. dePaula, H.B. Vo, Observed solar radio burst effects on GPS/wide area augmentation system carrier-to-noise ratio. Space Weather 4, S10006 (2006). doi:10.1029/2006SW000254 
A.P. Cerruti, P.M. Kinter, D.E. Gary, A.J. Mannucci, R.F. Meyer, P. Doherty, A.J. Coster, Effect of intense 2006 solar radio bursts on GPS receivers. Space Weather 6, S10D07 (2008). doi:10.1029/ 2007SW000375

A.D. Chave, A.G. Jones (eds.), The Magnetotelluric Method (Cambridge University Press, Cambridge, 2012)

M.N. Chigomezyo, A. Pulkkinen, M.L. Mays, M.M. Kuznetsova, A.B. Galvin, K. Simunac, D.N. Baker, X. Lin, Y. Zheng, A. Glocer, Simulation of the 23 July 2012 extreme space weather event: What if this extremely rare CME was Earth directed? Space Weather 11, 671 (2013). doi:10.1002/2013SW000990

C.R. Clauer, G. Siscoe, The great historical geomagnetic storm of 1859: A modern look. Adv. Space Res. 38, 117 (2006)

K.J. Clement, Das Große Nordlicht in der Nacht zun 29 Aug. 1859 und die Telegraphenverwirrung in Nordamerica und Europa (Perthes-Besser und Mauke, Hamburg, 1860)

E.B. Clements, A.K. Carlton, C.J. Joyce, N.A. Schwadron, H.E. Spence, X. Sun, K. Cahoy, Interplanetary space weather effects on lunar reconnaissance orbiter avalanche photodiode performance. Space Weather 14, 343-350 (2016). doi:10.1002/2016SW001381

E.W. Cliver, The 1859 space weather event: Then and now. Adv. Space Res. 38, 119 (2006). doi:10.1016/ j.asr.2005.07.077

R.S. Culley, Handbook of Practical Telegraphy (Longmans, Green, Reader, and Dyer, London, 1874)

P. Czech, C.H. Huynh, A. Dutil, The hydro-Quebec system blackout of March 13, 1989: System response to geomagnetic disturbance, in Proc. Geomagnetically Induced Currents Conf., EPRI, Palo Alto, CA (1989)

W.F. Davidson, The magnetic storm of March 24, 1940-Effects in the power system, Edison Electric Institute Bulletin, p. 365, July 1940

Electro-Magnetic Telegraphs, The Railway Magazine 33, 365 (1838)

M.D. Fagen, A History of Science and Engineering in the Bell System (Bell Telephone Laboratories, Inc., Murray Hill, 1975)

H.B. Garrett, A.C. Whittlesey, Guide to Mitigating Spacecraft Charging Effects (Wiley, Hoboken, 2012)

C.T. Gaunt, Why space weather is relevant to electrical power systems. Space Weather 14, 2-9 (2016). doi:10.1002/2015SW001306

L.W. Germaine, The magnetic storm of March 24, 1940-Effects in the communication system, Edison Electric Institute Bulletin, p. 367, July 1940

J.S. Gordon, A Thread Across the Ocean: The Heroic Story of the Transatlantic Cable (Harper, New York, 2003)

D. Hastings, H. Garrett, Spacecraft-Environment Interactions (Cambridge University Press, Cambridge, 2004)

A. Hewish, James Stanley Hey, M.B.E. 3 May 1909-27 February 2000. Biogr. Mem. Fellows R. Soc. 48, 167-178 (2002)

L.G. Jacchia, Variations in the Earth's upper atmosphere as revealed by satellite drag. Rev. Mod. Phys. 35, 973 (1963)

J.B.L. Jones, R.D. Bentley, R. Hunter, R.H.A. Iles, G.C. Taylor, D.J. Thomas, Space weather and commercial airlines. Adv. Space Res. 36, 2258 (2005)

J.G. Kappenman, Geomagnetic storms and their impact on power systems. IEEE Power Eng. Rev. 16, 5 (1996)

J.G. Kappenman, An overview of the impulsive geomagnetic field disturbances and power grid impacts associated with the violent Sun-Earth connection events of 29-31 October 2003 and a comparative evaluation with other contemporary storms. Space Weather 3, S08C01 (2005)

R. Kataoka, Y. Nakagawa, T. Sato, Radiation dose of aircrews during a solar proton event without groundlevel enhancement. Ann. Geophys. 33, 75-78 (2015). doi:10.5194/angeo-33-75-2015

M.A. Kelly, J.M. Comberiate, E.S. Miller, L.J. Paxton, Progress toward forecasting of space weather effects on UHF SATCOM after Operation Anaconda. Space Weather 12, 601-611 (2014). doi:10.1002/ 2014SW001081

W.T. Lord Kelvin, Presidential address to the Royal Society. Nature 47 (1892)

D. King-Hele, A Tapestry of Orbits (Cambridge University Press, Cambridge, 1992)

D.J. Knipp, Forward to space weather collection on geomagnetically induced currents: Commentary and research. Space Weather 13, 742 (2015). doi:10.1002/2015SW001318

D.J. Knipp, Essential science for understanding risks from radiation for air line passengers and crews. Space Weather 15, 549-552 (2017). doi:10.1002/2017SW001639

D.J. Knipp, W.K. Tobiska, B.A. Emery, Direct and indirect thermospheric heating sources for solar cycles 21-23. Sol. Phys. 224, 495 (2004). doi:10.1007/s11207-005-6393-4

D.J. Knipp, A.C. Ramsey, E.D. Beard, A.L. Borright, W.B. Cade, I.M. Hewins, R.H. McFadden, W.F. Denig, L.M. Kilcommons, M.A. Shea, D.F. Smart, The May 1967 great storm and radio disruption event: Extreme space weather and extraordinary responses. Space Weather 14, 614-633 (2016). doi:10.1002/ 2016SW001423 
L.J. Lanzerotti, C.H. Sayres, L.V. Medford, J.S. Kraus, C.G. Maclennan, D.J. Thomson, Statistical examination of induced voltages across long oceanic telecommunications cables, in Proceedings of the Workshop Solar-Terrestrial Predictions-IV, Ottawa, Canada, May 18-22, 1992, vol. 1 (NOAA Environ. Res. Lab., Boulder, 1993), p. 224

L.J. Lanzerotti, K. LaFleur, C.G. Maclennan, D.W. Maurer, Geosynchronous spacecraft charging in January 1997. Geophys. Res. Lett. 25, 2967 (1998)

Life Magazine, Spots on the face of the sun mess up earth's communications, 8, p. 38, April 8, 1940

D. Lindley, Degrees Kelvin, a Tale of Genius, Invention, and Tragedy (Joseph Henry Press, Washington, 2004)

W. Lohmeyer, A. Carlton, F. Wong, M. Bodeau, A. Kennedy, K. Cahoy, Response of geostationary communications satellite solid-state power amplifiers to high-energy electron fluence. Space Weather 13, 298-315 (2015)

G. Marconi, Radio communication. Proc. IRE 16, 40 (1928)

S. Matsushita, Dynamo currents, winds, and electric fields. Radio Sci. 4, 771-780 (1969). doi:10.1029/ RS004i009p00771

A.G. McNish, The magnetic storm of March 24, 1940. J. Geophys. Res. 45, 359 (1940)

L.V. Medford, L.J. Lanzerotti, J.S. Kraus, C.G. Maclennan, Transatlantic Earth potential variations during the March 1989 magnetic storm. Geophys. Res. Lett. 16, 1145 (1989)

A. Meloni, L.J. Lanzerotti, G.P. Gregori, Induction of currents in long submarine cables by natural phenomena. Rev. Geophys. 21, 795 (1983)

A. Meloni, L.J. Lanzerotti, L.V. Medford, Geomagnetic anomaly detected at hydromagnetic wave frequencies. J. Geophys. Res. 90, 3569 (1985). doi:10.1029/JB090iB05p03569

K. Moe, M.M. Moe, Operational models and drag-derived density trends in the thermosphere. Space Weather 9, S00E10 (2011)

National Academies, Severe Space Weather Events-Understanding Societal and Economic Impacts: A Workshop Report (2008)

S.B. Nicholson, The great magnetic storm of March 24, 1940. Publ. Astron. Soc. Pac. 52, 169 (1940)

S. Odenwald, Solar Storms, Washington, 2015, www.astronomycafe.net

S. Odenwlad, Newspaper reporting of space weather: End of a golden age. Space Weather 5, S11005 (2007). doi:10.1029/2007SW000344

V.L. Pisacane, The Space Environment and Its Effects on Space Systems (AIAA, Reston, 2016)

G.B. Prescott, Observations made at Boston, Mass, and its vicinity. Am. J. Sci. 29, 92 (1860)

G.B. Prescott, Theory and Practice of the Electrical Telegraph (Osgood and Co., Boston, 1875)

A. Pulkkinen, E. Bernaubeu, J. Eichner, C. Beggan, A.W.P. Thomson, Generation of 100-year geomagnetically induced current scenarios. Space Weather 10, S04003 (2012)

C.V. Reeves, Limitations imposed by geomagnetic variations on high quality aeromagnetic surveys. Explor. Geophys. 24, 115 (1993)

W.J. Rooney, Earth Current Results at Tucson Magnetic Observatory (1932-1942), vol. 9 (Carnegie Institution of Washington, Washington, 1949), 309 pp., Issue 175

T. Rowe, Connecting the Continents (Creative Publishers, St. John's, Newfoundland, 2009)

Royal Academy of Engineering, Extreme Space Weather: Impacts on Engineered Systems and Infrastructure (2013)

M.A. Shea, D.F. Smart, Compendium of the eight articles on the "Carrington Event" attributed to or written by Elias Loomis in the American Journal of Science 1859-1861. Adv. Space Res. 38, 313 (2006). doi:10.1016/j.asr.2006.07.005

K. Silverman, Lightning Man: The Accursed Life of Samuel F.B. Morse (Knopf, New York, 2003)

G. Siscoe, N.U. Crooker, C.R. Clauer, Dst of the Carrington storm of 1859. Adv. Space Res. 38, 173 (2006). doi:10.1016/j.asr.2005.02.102

T. Standage, The Victorian Internet (Walker and Co., New York, 1998)

G. Swedenborg, K. Wyke, Disturbances caused by Earth currents to telecommunication plants. Tele 1, 41 (1959)

R.R. Taur, Ionospheric scintillation at 4 and 6 GZ. COMSAT Tech. Rev. 3, 145-163 (1973)

R.R. Taur, Simultaneous 1.5- and 4-GHz ionospheric scintillation measurement. Radio Sci. 11, 1029-1036 (1976)

W.K. Tobiska et al., Global real-time dose measurements using the automated radiation measurements for aerospace safety (ARMAS) system. Space Weather 14, 1053-1080 (2016). doi:10.1002/ 2016SW001419

B.T. Tsurutani, W.D. Gonzalez, G.S. Lakhina, S. Alex, The extreme magnetic storm of 1-2 September 1859. J. Geophys. Res. 108, 1268 (2003). doi:10.1029/2002JA009504

A.L. Vampola, Thick dielectric charging of high-altitude spacecraft. J. Electrost. 20, 21-30 (1987)

J.A. Van Allen, The geomagnetically trapped corpuscular radiation. J. Geophys. Res. 64, 1683-1689 (1959) 
A. Viljanen, A. Pulkkinen, R. Pirjola, K. Pajunpaa, P. Posio, A. Koistinen, Recordings of geomagnetically induced currents and nowcasting service of the Finnish natural gas pipeline system. Space Weather $\mathbf{4}$ (2006)

G. Weightman, Signor Marconi's Magic Box (DaCapo Press, Perseus Books, Boston, 2003)

M. Wik, R. Pirjola, H. Lundstedt, A. Viljanen, P. Wintoft, A. Pulkkinen, Space weather effects in July 1982 and October 2003 and the effects of geomagnetically induced currents on Swedish technical systems. Ann. Geophys. 27, 1775 (2009) 